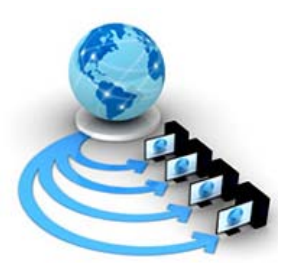

Volume 8, No. 9, November-December 2017

International Journal of Advanced Research in Computer Science

RESEARCH PAPER

\author{
Available Online at www.ijarcs.info
}

\title{
CONSTRAINT TIME MINIMIZING ASSIGNMENT PROBLEM - GENETIC ALGORITHM
}

\author{
K.Chandra Kala \\ Department of CSE \\ Vignan Nirula Institute of Technology \& Science for \\ Women, Guntur (Dt), Andhra Pradesh, India
}

\author{
K.Sobhan Babu \\ Professor of Mathematics \\ JNTUK-UCEN, Narasaraopet \\ Guntur (Dt), Andhra Pradesh, India
}

\begin{abstract}
In this paper we present a new method for a problem called constraint Time minimizing Assignment problem. The proposed method uses the well-known Genetic algorithm.
\end{abstract}

Keywords: Assignment Problem, Time Constraint, Genetic Algorithm,

\section{INTRODUCTION}

The time minimizing assignment problem (TMAP) is another important class of assignment problem. TMAP has been considered by many researchers like refer the reader to [1], [2], and [3], under the usual assumption that work in all the $\mathrm{n}$ jobs commence simultaneously. A generalized version of TMAP where $n$ jobs are considered to be partitioned into $\mathrm{p}(<\mathrm{n})$ blocks with precedence constraints on the jobs and blocks. In one case, occupations in each square are performed in some successive request however the different pieces can be started all the while, where as in other case the employments inside each piece are initiated all the while yet the $\mathrm{p}$ squares are finished in a consecutive request. These two generalizations, when either $p=1$ (or) $p=n$ are equivalent to either the cost minimizing assignment problem (CMAP) or the TMAP, and thus solvable in polynomial time. However, when $1<\mathrm{p}<\mathrm{n}$, the usual solution procedures are not applicable. Using the domination characters, developed algorithms that are more efficient then the known Branchand-Bound algorithms for these TMAP under categorization [4].

\section{PROBLEM}

There are $\mathrm{I}=\{1,2,3, \ldots \ldots, \mathrm{m}\}$ set of $\mathrm{m}$ persons, $\mathrm{J}=\{1,2,3, \ldots \ldots, \mathrm{n}\}$ set of $\mathrm{n}$ jobs and $\mathrm{K}=\{1,2,3, \ldots, \mathrm{p}\}$ set of $\mathrm{p}(<\mathrm{n})$ facilities, $\mathrm{T}(\mathrm{i}, \mathrm{j}, \mathrm{k})$ is the time that ith person takes to complete the jth job using facility $\mathrm{k}$ is known. Out of the given $n$ jobs only $n^{1}(<n)$ are to be assigned to $m$ persons. It is given that

(1) $n^{1}>\mathrm{m}$

(2) ith person has to do $m_{i}$ jobs such that $\sum_{i \in I} m_{i}=n^{1}$

(3) A job cannot be assigned to more than one person

(4) All the persons start working on the jobs simultaneously.

(5) The cumulative times of the $m_{i}$ jobs assigned to ith person is the complete time of the ith person.

(6) A subset of jobs which are not be allotted to a person is given.
(7) There are $p$ facilities and each person is restricted not to utilize the facilities more than a given number of times.

(8) The Completion time of the $n^{1}$ jobs is the maximum among $\mathrm{m}$ persons complete times.

The problem is to assign those $n^{1}$ jobs to $\mathrm{m}$ persons with minimum total time with the above restrictions satisfies.

\section{MATHEMATICAL FORMULATION}

The solution $X(i, j, k), i, j, k \quad I \times J \times K$

$\mathrm{X}(\mathrm{i}, \mathrm{j}, \mathrm{k})=1, \quad$ if the $\mathrm{j}^{\text {th }}$ job is assigned to the $\mathrm{i}^{\text {th }}$ person at $\mathrm{k}^{\text {th }}$ facility

$=0$, otherwise.

Then the problem can be stated as: $\operatorname{MIN}_{X}\{T(X)\}$

$W$ here $T(X)=\max _{i \in I} \sum_{j \in J} \sum_{k \in K} T(i, j, k) . X(i, j, k)$

Subject to:

$$
\sum_{i \in I} \sum_{k \in K} X(i, j, k)=1, j \in J
$$

$$
\begin{aligned}
& \sum_{j \in J} \sum_{k \in K} X(i, j, k)=m_{i}, i \in I \\
& \sum_{k \in K} \sum_{j \in J} X(i, j, k) \leq p_{1}, i \in I \\
& \sum_{i \in I} \sum_{j \in J} \sum_{k \in K} X(i, j, k)=n^{1}
\end{aligned}
$$

$$
\begin{aligned}
& X(i, j, k)=0(\text { or }) 1,(i, j, k) \in I \times J \times K \\
& \begin{array}{c}
\text { CR }(\mathrm{i}, \mathrm{j})=1, \text { If } \mathrm{j}^{\text {th }} \text { job cannot assign } \mathrm{i}^{\text {th }} \text { person; } \\
=0, \text { otherwise }
\end{array}
\end{aligned}
$$

If $\mathrm{CR}\left(\mathrm{i}_{1}, \mathrm{j}_{1}\right)=1$, then $\mathrm{X}\left(\mathrm{i}_{1}, \mathrm{j}_{1}, \mathrm{k}\right)=0$ for $\mathrm{k}=1,2,3, \ldots \ldots, \mathrm{m}$

Where $\quad \mathrm{i}=\{1,2,3, \ldots, \ldots, \mathrm{m}\} \quad, \mathrm{j}=\{1,2,3, \ldots \ldots, \mathrm{n}\} \quad$ and $\mathrm{k}=\{1,2,3, \ldots \ldots, \mathrm{p}\}$ respectively are the sets of persons, jobs 
and facilities and $T(\mathrm{i}, \mathrm{j}, \mathrm{k})$ is the time that ith person takes to complete the jth job using facility $\mathrm{k}$ is known.

$\mathrm{X}=\mathrm{X}(\mathrm{i}, \mathrm{j}, \mathrm{k})$ is feasible Assignment if it satisfies all the above conditions.

The three dimensional problem converted into two dimensional problem and then applied Genetic algorithms. The definitions and algorithms are presented in the following.

\section{DEFINITIONS}

Genetic Algorithm: The phrasing of Genetic algorithm is an odd blend of Computer Science and Genetics. Genetic algorithms are scan calculations for finding ideal or close optima arrangements. For a fantastic prologue to Genetic algorithms, we allude the peruser to [5], [6] and [7]. Generally, arrangements are spoken to in double as series of $1 \mathrm{~s}$, yet different encodings are likewise conceivable. The development for the most part begins from a populace of haphazardly created people and occurs in ages. In every age, the wellness of each person in the populace is assessed, different people are stochastically chosen from the present populace (in light of their wellness), and adjusted (recombined and conceivably arbitrarily changed) to shape another populace. The new population is then used in the next iteration of the algorithm. Ordinarily, the calculation ends when either a greatest number of ages has been created, or a palatable wellness level has been gone after the populace. On the off chance that the calculation has ended because of a greatest number of ages, an agreeable arrangement might possibly have been come to [8].

Chromosomes: A structure in the nucleus containing a linear thread of DNA which transmits genetic information and associated with RNA and his tones. An individual's genetic structure is described by bit strings as a list of 1's and 0 's. These strings termed as chromosomes.

Alleles: One of two or more alternative forms of a gene at corresponding site (loci) of homogeneous chromosomes which determine alternative characters in inheritance. Chromosomes strings containing bits are called alleles.

Genotype: The entire genetic construction of an individual, also, the alleles present at one or more specific loci. The bit string associated with a given individual genotype.

Generation: (i) The process of reproduction. (ii) A class made out of all people expelled by a similar number of progressive precursors from regular ancestors.

Reproduction: The creation of posterity by composed bodies, people from one age are chosen for people to come.

Crossover: The trading of material between homologous chromosomes amid the primary meiotic division bringing about new mix of qualities. Hereditary material from one individual is traded with hereditary material of another person.

Mutation: A lasting transmissible change in hereditary material.

\section{SOLUTION PROCEDURE}

Genetic Algorithms (GA) are modernized pursuit and enhancement calculations in light of the mechanics of regular hereditary qualities and normal determination. They were first imagined by John Holland and were consequently created by different specialists. Every potential arrangement is encoded as a string and a populace of strings is made which is additionally prepared by three administrators: Reproduction, Crossover and Mutation. Generation is a procedure in which singular strings are replicated by their wellness work. (Here the wellness work is taken to be the aggregate cost work). Hybrid is the way toward swapping the substance of two strings at some point(s) with a likelihood. At long last, Mutaiton is the way toward flipping the incentive at a specific area in a string with a low likelihood.

1. The string is characterized as $\mathrm{Cij}$ where $\mathrm{I}$ and $\mathrm{j}$ are line and section and $\mathrm{C}$ is taken a toll.

\section{Compose Cij in bit string, a rundown of 1 's and 0 's}

3. The determination of person's genotype relies upon the biggest estimation of cost and genotype is permitted two off springs and the littlest estimation of cost isn't fit, put this privilege contiguous most noteworthy esteem.

4. Put the rest of the genotypes to right and left by estimation of cost in diminishing request.

5. Three genetics operators are applied to produce the next generation solution (chromosome). These administrators are determination/propagation, hybrid and change.

6. Again take the genotype for up and coming age of second line of above come back to step.

7. Put the rest of the genotypes of third and fourth line for propagation, after fulfillment of all means, pick the most elevated estimation of bits to make the circle Cij cost and draw vertical line of Jth segment. Presently take estimation of cost of outstanding column.

\section{COMPUTATIONAL EXPERIENCE}

The program was developed for the test problem, in this two cases were implemented. One in which inversion was used and another in which Inversion was not used. In the two cases, the appropriate response focalized to the last ideal esteem. On a normal, there was very little distinction in the quantity of emphasess required to achieve the last an incentive in both the cases. On a normal, the time taken was 0.01 measured on a standard desktop with processor Intel Pentium 4, 2.40GHz. The populace estimate at every age was kept equivalent to 20 .

\section{CONCLUSION}

An exploratory examination concerning tackling the Assignment demonstrate utilizing Genetic Algorithm is introduced. Different parameters influencing the calculation are examined and their effect on meeting to the last ideal arrangement is appeared. 


\section{ACKNOWLEDGMENT}

The authors are thankful to referees for their enormous suggestions to publish this work.

\section{REFERENCES}

[1] R.S.Garfinkel, "An improved algorithm for bottleneck assignment problem”, Operations Research 18 (1971), $1717-1751$

[2] Shalini Arora, M.C.Prui, "A variant of time minimizing assignment problem", European Journal of Opearions Research 110(1998) 314-325.

[3] Anshuman Sahu, Rudrajit Tapadar, "Solving the Assignment problem using Genetic algorithm and Simulated Annealing", IAENG International Journal of Applied Mathematics, 36:1, IJAM_36_1_7. 1 February 2007.
[4] Fredric S. Hillier, Gerald J. Lieberman, Introduction to Mathematical Programming, 2 nd ed, Mac Graw-Hill Inc. 1995, pp.45-58.

[5] Goldberg .D.E. Genetic Algorithms in search, Optimization and Machine Learning, Addison-Wesley, 1989.

[6] Melanie Mitchell , An introduction to Genetic Algorithms, The MIT Press, 1999, pp.79-108.

[7] Thomas Dean, James Allen and Yiannis Aloimounos, Artificial Intelligence: Theory and Practice, 1 st ed, Addison-Wesley, January 10, 1995.

[8] Eiben. A. E, P-E.Raue, Zsofia Ruttkay "Genetic algorithms with multi-parent recombination". Proceedings of the 3rd Conference on Parallel Problem Solving from Nature,LNCS 866, Springer-Verlag, 1994, pp. 78-87. 